\title{
Objeto de aprendizagem sobre cultura digital: fake news e filtros bolha
}

\author{
Gabriel Rocha de Oliveira \\ Universidade Federal da Grande Dourados - UFGD \\ Dourados, Mato Grosso do Sul, Brasil \\ gabrieloliveira040@gmail.com
}

\author{
Valguima Victoria Viana Aguiar Odakura \\ Universidade Federal da Grande Dourados - UFGD \\ Dourados, Mato Grosso do Sul, Brasil \\ valguima.odakura@gmail.com
}

\section{RESUMO}

In a society inserted in the digital environment, where children are exposed daily to different types of content, there is a need to guide children, especially in relation to digital citizenship. In this context, this work aims to develop a Learning Object (LO) that helps discuss fake news and bubble filters in a playful way, encouraging elementary school children to have a critical view on the topic. To qualify whether this LO achieved its objective, two methods of evaluation were used with the intention of verifying whether the proposed LO fulfills its role in raising the target audience's awareness.

\section{KEYWORDS}

Learning Object, Fake News, Bubble Filters.

\section{INTRODUÇÃO}

A cidadania digital, segundo Carvalho et al. [1], deve ser vista como uma ampliação da cidadania tradicional, sendo que o que diferencia ambas é o espaço e como ela é exercida. Se pensarmos no espaço digital como um meio em que nossa sociedade se encontra inserida atualmente e no qual crianças desde muito cedo, já estão participando em redes sociais e encontram-se expostas a diversos tipos de conteúdos, é de suma importância que se tenham recursos educativos que possam ensinar essas crianças a se conscientizarem dos perigos que o mundo virtual pode conter.

O tema proposto para esse trabalho se origina da necessidade de desenvolver materiais que auxiliem no combate das fake news. Segundo Allcott e Gentzkow [2] fake news são notícias que são intencional e comprovadamente falsas, além de terem o objetivo de enganar o leitor. De acordo com Magrani [3], filtro bolha é: "um conjunto de dados gerado por todos os mecanismos algorítmicos utilizados para se fazer uma edição invisível voltada à customização da navegação online".

Diante de todo esse cenário, ainda existe mais um tema que é frequentemente abordado quando se refere à fake news e filtros bolha que é a pós-verdade. Segundo o Dicionário Oxford ${ }^{1}$ o termo pós-verdade tem como significado: "aquilo que se relaciona ou que denota circunstâncias nas quais fatos objetivos são menos influentes em moldar a opinião pública do que apelos à emoção e à crença pessoal". Sendo assim, os indivíduos que disseminam tal conceito, têm em mente que estão espalhando a verdade absoluta, contudo estão apenas propagando a sua ideia sobre o assunto.

Com a intenção de evitar a propagação das fake news e a conscientização em relação aos filtros bolha, cria-se a necessidade de

\footnotetext{
${ }^{1}$ Dicionário Oxford, disponível em: https://en.oxforddictionaries.com/definition/us/posttruth
}

produzir Objetos de Aprendizagem (OA) que atuem nessa conscientização. Wiley [4] define objeto de aprendizagem como: "um recurso digital que pode ser reusado para apoiar a aprendizagem”.

O presente trabalho trata do desenvolvimento e avaliação de um OA, que aborde os temas fake news e filtros bolha. O OA foi escolhido pois o público-alvo são crianças do ensino fundamental II, e pretende-se abordar o tema de maneira lúdica.

O restante deste artigo está organizado da seguinte forma: na Seção 2 é apresentada a fundamentação teórica. Na Seção 3 são expostos os trabalhos relacionados. Na Seção 4 a metodologia utilizada é descrita. Na Seção 5 a avaliação do OA é relatada. Na seção 6 são retratados os resultados obtidos através da avaliação na seção anterior. Por fim, na Seção 7 são apresentadas a conclusão do trabalho e indicação de trabalhos futuros.

\section{FUNDAMENTAÇÃO TEÓRICA}

Na obra de Pariser [5] é retratado como os filtros bolha são inseridos no cotidiano das pessoas, sendo que uma vez dentro dos mesmos, torna-se uma tarefa difícil realizar a distinção do seu grau de parcialidade, ou seja, não se sabe se o que está sendo mostrado, reflete de fato o que queremos ver. Pariser [5] diz que podemos ter três dinâmicas diferentes que nunca havíamos lidado: a princípio estamos sozinhos dentro uma bolha, onde os interesses mais específicos são compartilhados e assim criam-se filtros que acabam afastando as pessoas; temos que o filtro bolha é algo invisível, sendo que quando pessoas distintas pesquisam o mesmo assunto, dependendo dos seus interesses, históricos, orientações políticas e demais aspectos, faz com que sejam mostradas informações diferentes para a mesma pesquisa; além disso, não são as pessoas que escolhem em qual bolha querem se encaixar, esses filtros veem até os usuários e são moldados para que seja difícil sair deles.

Complementando o estudo de Pariser [5], o trabalho de Branco [6] retrata como os filtros bolha são criados, especialmente na rede social Facebook ${ }^{\circledR 2}$. Tendo em vista que o Facebook é uma rede social muito popular com um grande número de usuários, percebe-se que ela pode ser utilizada pelos criadores de fake news para espalhar desinformação, visto que, em 2017, Branco [6] relata que aproximadamente $70 \%$ dos brasileiros se informavam através da rede social. Dessa forma, cria-se uma bolha que limita o que o usuário recebe, ficando restrito a um determinado grupo de amigos que compartilham das mesmas ideologias, dessa maneira esses sujeitos ficam cada vez mais afastados de pessoas com opiniões contrárias a dela. No trabalho é proposta a realização da alfabetização digital, em que Branco afirma que através da educação e do uso consciente da tecnologia, pode ser possível melhorar nossa percepção do assunto e assim mudar essa perspectiva. O autor também propõe a busca

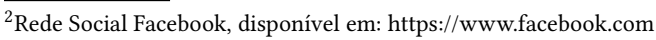


pelo esclarecimento, e a constante averiguação da veracidade das informações.

No contexto da alfabetização digital proposta por Branco [6], pode-se utilizar como instrumento, os objetos de aprendizagem, que são recursos digitais para apoio do processo de ensino-aprendizagem $[6,7]$. Os OAs podem ser textos, animações, vídeos, imagens, aplicações Web, entre outros [7].

Braga e Menezes [7] apontam que os OAs possuem duas perspectivas, sendo: a pedagógica e a técnica. Na perspectiva pedagógica, possui orientações que facilitam a concepção desse OA, em que são considerados aspectos como a interatividade com o estudante, a cooperação entre estudantes, dentre outros. Em relação as características técnicas, algumas dos itens considerados são disponibilidade, acessibilidade e usabilidade. Braga e Menezes [7] ressaltam que que nem todos os OAs atendem todas as características. Contudo, quanto mais características possuir, maior será a sua reutilização.

\section{TRABALHOS RELACIONADOS}

O trabalho de Abreu et al. [8], realiza uma análise sobre o jogo CHEQUE ISSO!, que apresenta um jogo no estilo RPG, sigla de origem inglesa que tem como significado: Role-Playing Game (Jogo de Interpretação de Personagem) em português. O jogo é composto por 25 cartas e um guia de checagem de fatos. Para jogar, os estudantes são contextualizados sobre a missão do jogo, é realizada a entrega de uma carta e um guia para cada estudante desempenhar a atividade, na qual o mesmo pode realizar uma consulta na Internet e discutir em grupo as informações. Com o fim da verificação, os componentes de cada grupo realizam uma comparação e assim chegam a uma decisão sobre o que deveria ser feito a respeito da informação apurada. Desta forma, o jogo CHEQUE ISSO!, apesar de suas limitações linguísticas para ser aplicado no Brasil, possui recursos para conduzir o enfrentamento da disseminação defake news entre os estudantes e assim criar um hábito de checagem das informações.

O longa-metragem 'Tito e os pássaros' trata da história de um menino, denominado Tito, que tem como missão salvar o mundo de uma epidemia que faz com que as pessoas fiquem adoecidas quando apresentam medo. Premiado como melhor animação nos festivais internacionais de Chicago e de Havana, a equipe responsável pelo filme desenvolveu um jogo ${ }^{3}$ intitulado "Tito e os pássaros - O celular do surto", onde o usuário com auxílio do Tito e seus amigos deve impedir que o surto do medo se propague. $\mathrm{O}$ jogo baseia-se na verificação de mentiras que estão sendo espalhadas na Internet através dos aplicativos Fakebook, Twistter e InstaPanic. No aplicativo Fakebook quando o usuário abre uma publicação, ele deve avaliar com Like caso seja verdadeira ou com Dislike se ela for falsa. Para o jogador verificar se a notícia é falsa, ele deve clicar em um botão denominado Checar fontes, após a checagem o usuário deve tomar a sua decisão. No aplicativo InstaPanic o jogador deve checar quais imagens são verdadeiras e quais são montagens, enquanto no app Twistter o usuário deve identificar quais assuntos podem ser replicados. Ao cumprimento de cada tarefa uma resposta é enviada em forma de feedback através do aplicativo Zap Messenger, sendo uma mensagem positiva para o acerto ou uma negativa para o erro.

${ }^{3}$ Tito e os pássaros - $\mathrm{O}$ celular do surto, disponível em http://titoandthebirds.com/game/\#/pt-br
Além desse feedback, caso a resposta esteja errada, o jogador perde uma porção da "barra de vida", caso a mesma chegue ao fim, o surto não foi contido.

No jogo CHEQUE ISSO!, em Abreu et. al. [8], o objetivo é conscientizar sobre fake news e orientar para a checagem de informações. Já o jogo "Tito e os pássaros - O celular do surto"tem como propósito alertar sobre os perigos da Internet através de aplicativos conhecidos. O presente trabalho, de forma semelhante aos anteriormente relatados, objetiva trabalhar a conscientização sobre o uso da Internet, especificamente no enfrentamento das fake news e filtro bolha. De forma distinta dos trabalhos abordados, neste trabalho propõe-se o desenvolvimento de um OA que irá realizar a simulação de uma rede social muito conhecida, o facebook, em que o usuário deve identificar possíveis fake news escondidas através de publicações, bem como estar ciente dos filtros bolha.

\section{METODOLOGIA}

Neste trabalho relata-se o desenvolvimento de um objeto de aprendizagem, com o propósito de conscientizar de forma lúdica estudantes do ensino fundamental II, para que possam saber identificar possíveis fake news e assim, com os conhecimentos adquiridos, buscar sua veracidade, além de conscientizar sobre filtros bolha.

A inspiração para o desenvolvimento do OA foi baseada na rede social Facebook ${ }^{\circledR}$ e no jogo "Tito e os pássaros - O celular do surto". A proposta do desenvolvimento é que o OA aproxime-se da rede social Facebook, uma vez que esta é o meio principal de informações dos brasileiros [6].

O OA é composto por quatro publicações fictícias, das quais três publicações possuem mensagens com informações falsas com a intenção de provocar reflexão ao usuário para que ele não compartilhe fake news, enquanto uma publicação com uma notícia comprovadamente verdadeira.

Quando o usuário entra no OA ele encontrará uma tela inicial com o nome do OA desenvolvido, logo em seguida, ele avançará para a próxima página em que é apresentado ao Fakebuqui e aos termos que abrangem esse trabalho, em seguida é apresentado às instruções de como navegar através do OA.

Na publicação 1 o usuário possui duas opções: verificar ou não verificar a publicação. Caso ele opte por verificar, o OA simula uma busca em um motor de pesquisa e assim verifica a fonte em um endereço Web previamente definido. Caso o usuário opte por não verificar, é encaminhado para a página de resposta da publicação, na qual ele deve escolher se aquela publicação é verdadeira ou uma fake news. Após a escolha é gerado um feedback para a resposta escolhida, informando e explicando se aquela escolha está certa ou errada, não havendo distinção se o usuário buscou verificar ou não aquela informação. A princípio foi desenvolvido um feedback apenas para o acerto ou erro, não foi elaborado um feedback específico para cada ação do usuário. Na Figura 1 encontra-se o mapa de navegação do OA. Nele, retrata-se apenas o fluxo da publicação 1, contudo as demais publicações possuem o mesmo caminho a ser seguido.

Quando o usuário chega na etapa de avaliar a publicação, como pode ser visto na Figura 2, há a opção de escolher se a publicação é verdadeira ou se é uma fake news. Para cada escolha é fornecido um feedback individual sobre o acerto ou erro, a fim de informar e conscientizar sobre a propagação das fake news. 


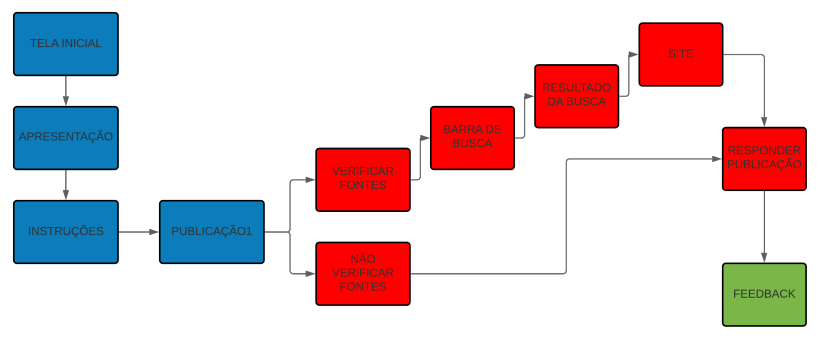

Figura 1: Etapa de arquitetura: mapa de navegação.

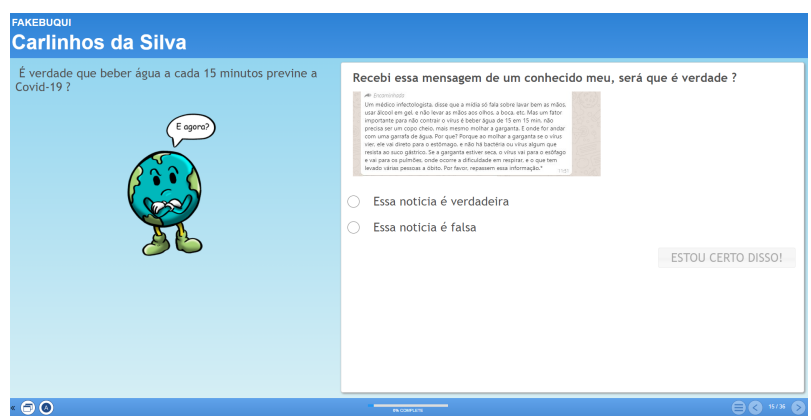

Figura 2: Publicação do Fakebuqui.

Com o intuito de deixar o OA mais atrativo para os estudantes, foi concebido um mascote denominado Bolinha como pode ser visualizado na Figura 3. Seu objetivo é acompanhar o estudante ao decorrer do percurso das publicações, aconselhando a verificar as fontes de tais notícias e sinalizando os recursos que devem ser utilizados.

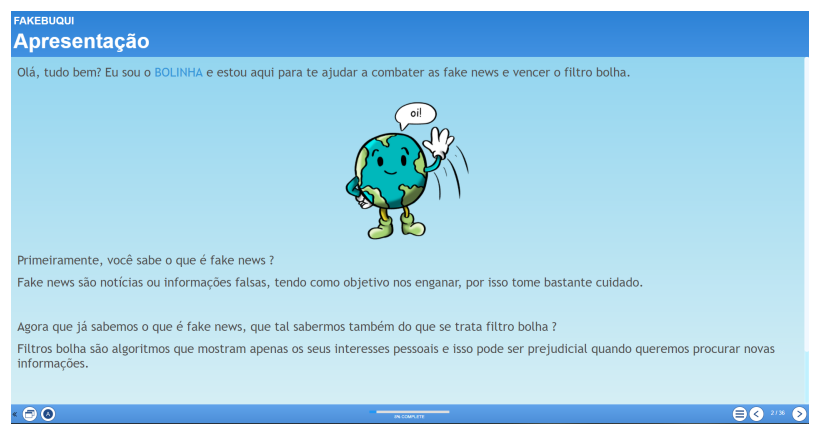

Figura 3: Mascote do OA.

A ferramenta de autoria (FA) escolhida para o desenvolvimento do OA foi o Xerte ${ }^{4}$. Segundo Batistella [9] o Xerte é uma FA sob licença pública GNU. Essa FA possui suporte a recursos multimídias, tais como: imagens e vídeos, além de suportar incorporação de conteúdos da Web.

O OA desenvolvido encontra-se disponível no site Ponte Educacional $^{5}$

\footnotetext{
${ }^{4}$ Xerte, disponível em: https://xerte.org.uk/index.php/en/

${ }^{5}$ Fakebuqui, disponível em: https://ponteducacional.com.br/projetos/oas-fakebuqui/
}

\section{AVALIAÇÃO DO OBJETO DE APRENDIZAGEM}

Segundo Oliveira et al. [10] a avaliação de OAs deve ser realizada com o intuito de qualificar o OA desenvolvido, levando em consideração aspectos técnicos e pedagógicos com a finalidade de mensurar se o OA proposto atingiu seus objetivos.

Dentre os métodos de avaliação para OAs apresentados por Tsuda et al. [11] destacam-se dois, o método LORI e o EGameFlow. Vale ressaltar que Tsuda et al. [11] recomenda o uso de dois métodos complementares que englobem o público-alvo e especialistas. Neste trabalho, optou-se pelo LORI para os especialistas, estudantes da área da computação e professores, enquanto o EGameFlow para estudantes do $6^{\circ}$ ao $9^{\circ}$ ano do ensino fundamental II.

O LORI (Learning Objects Review Instrument) [12], trata-se de um método de avaliação de OAs que faz uso de nove heurísticas para realizar tal avaliação, segundo Tsuda et al. [11] essas heurísticas são:

i) Qualidade do conteúdo: veracidade, precisão, apresentação balanceada de ideias e nível apropriado de detalhes;

ii) Alinhamento com o objetivo de aprendizagem: o que foi aprendido era o desejado, atividades do objeto de aprendizagem consistentes com o seu objetivo;

iii) Feedback e adaptações: adaptação do objeto aos diferentes usuários, o perfil do usuário influencia no comportamento do objeto;

iv) Motivação: habilidade de motivar e interessar seus usuários;

v) Design de apresentação: a apresentação do objeto permite um aprendizado eficiente, cores, sons e elementos decorativos não interferem na finalidade do objeto de aprendizagem;

vi) Usabilidade e interação: facilidade de navegação, previsibilidade da interface, qualidade dos recursos de ajuda;

vii) Acessibilidade: projeto de controles e modo de jogo que acomodem pessoas com deficiência;

viii) Reusabilidade: capacidade de utilizar o objeto em diferentes contextos e com usuários de diversas origens;

ix) Conformidade com padrões: aderência a padrões e especificações internacionais.

O EGameFlow [13], é baseado no método GameFlow de [14] que procura explicar o que torna uma atividade agradável. Tsuda et al. [11] descreve que o EGameFlow visa criar uma escala de satisfação do utilizador com o sistema, para isso são necessários oito dimensões que contemplam os seguintes aspectos:

i) Concentração: visa verificar se o usuário manteve-se concentrado ao decorrer do OA;

ii) Desafios: verifica se o usuário aproveitou o OA sem se sentir entendiado;

iii) Autonomia: verifica se o usuário tem controle sobre o OA;

iv) Clareza dos objetivos: verifica se o OA possui clareza ao expor os objetivos, fazendo com que não existam dúvidas a respeito do que deve ser realizado;

v) Feedback: verifica se o OA apresenta informações a respeito do seu progresso;

vi) Imersão: verifica se o usuário se sente atraído pelo $O A$;

vii) Interação social: verifica se o OA possui recursos que possibilitam a comunicação entre os usuários; 
viii) Melhoria do conhecimento: verifica se o OA proposto contribui para o aumento do conhecimento do usuário.

Entretanto, cada dimensão possui diversos itens e neste trabalho foi realizada uma adaptação do método com o propósito de simplificar a avaliação por parte do público-alvo. $\mathrm{O}$ ajuste consiste em reduzir o número de itens de cada dimensão, sendo que do total de cinquenta e quatro itens que englobam as oito dimensões, apenas nove itens foram utilizados. Vale ressaltar que não houve a inclusão de nenhum item da dimensão Interação Social , visto que essa dimensão não foi trabalhada no OA.

A adaptação do método EGameFlow utilizada neste trabalho pode ser visualizada na Tabela 1 . A adaptação foi realizada para reduzir o número de itens na avaliação, uma vez que a mesma será aplicada com estudantes do ensino fundamental II.

Tabela 1: Adaptação do método EGameFlow.

\begin{tabular}{|c|c|}
\hline Concentração & Feedback \\
\hline $\begin{array}{c}\text { C1 - O jogo } \\
\text { prende } \\
\text { minha atenção? }\end{array}$ & $\begin{array}{c}\text { F2 - Recebo feedback } \\
\text { imediato } \\
\text { das minhas ações? }\end{array}$ \\
\hline Desafios & Imersão \\
\hline $\begin{array}{c}\text { H3 - Existem "dicas" } \\
\text { que ajudam } \\
\text { na tarefa? }\end{array}$ & $\begin{array}{c}\text { I6 - Me sinto } \\
\text { emocionalmente } \\
\text { envolvido com o jogo? }\end{array}$ \\
\hline Autonomia & Interação Social \\
\hline $\begin{array}{c}\text { A5 - Posso me recuperar } \\
\text { de qualquer } \\
\text { erro cometido? }\end{array}$ & $\begin{array}{c}\text { Melhoria } \\
\text { do Conhecimento }\end{array}$ \\
\hline $\begin{array}{c}\text { Clareza dos Objetivos } \\
\text { G1 - Objetivos gerais } \\
\text { apresentados } \\
\text { no início do jogo? }\end{array}$ & $\begin{array}{c}\text { K1 - O jogo melhora } \\
\text { o meu conhecimento? }\end{array}$ \\
\hline $\begin{array}{c}\text { G2 - Objetivos gerais } \\
\text { apresentados claramente? }\end{array}$ & $\begin{array}{c}\text { K2 - Capto as ideias } \\
\text { básicas do } \\
\text { conteúdo apresentado? }\end{array}$ \\
\hline
\end{tabular}

Para condução das avaliações foi desenvolvido um formulário online que contemplasse as dimensões de cada método, para isso foi usada uma escala variando de (1 - 5), sendo que quanto maior a nota, melhor é o desempenho naquela dimensão. Contudo, caso o avaliador considerasse o item não relevante ao $\mathrm{OA}$, ou se o avaliador não se sentisse qualificado para julgar aquele critério, poderia atribuir NA (Não Aplicável). Ao final do questionário, foi deixado um campo para sugestões de melhorias e/ou opiniões a respeito do OA.

\section{RESULTADOS}

A avaliação do OA foi realizada em separado para cada instrumento de avaliação. A aplicação do LORI, com especialistas, ocorreu de forma totalmente online. Os avaliadores foram contatados por email, no qual foi encaminhado um link do OA, bem como do formulário online do LORI. Participaram apenas seis entrevistados, sendo que quatro são acadêmicos de computação, uma pedagoga e um acadêmico de outra área de atuação. A Tabela 2 representa a legenda de identificação de cada avaliador do OA Fakebuqui.

Tabela 2: Perfil dos avaliadores do LORI.

\begin{tabular}{|c|c|c|c|}
\hline AVALIADOR & $\begin{array}{c}\text { Acadêmico } \\
\text { de } \\
\text { Computação }\end{array}$ & Professor & Outro \\
\hline A1 & & $\mathrm{X}$ & \\
\hline A2, A3, A4, A6 & $\mathrm{X}$ & & \\
\hline A5 & & & $\mathrm{X}$ \\
\hline
\end{tabular}

Na Figura 4 são mostradas as médias das notas atribuídas por cada avaliador para cada dimensão do método LORI. O desvio padrão nas médias do método LORI obteve uma variação de 0,4 até 0,54 pontos.

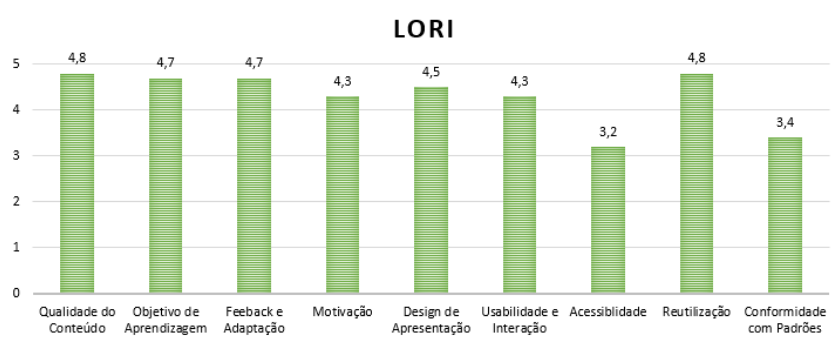

Figura 4: Média das dimensões avaliadas no LORI.

É possível perceber que as dimensões Qualidade do conteúdo e Reutilização obtiveram as melhores médias, 4,8 muito próxima da nota máxima 5. As dimensões Objetivo de aprendizagem e Feedback e adaptação obtiveram a segunda melhor média, 4,7, também muito próxima de 5. De maneira geral, o OA foi muito bem avaliado pelos especialistas, indicando que o mesmo está adequado para ser utilizado.

Vale ressaltar que as dimensões Acessibilidade e Conformidade com padrões obtiveram as menores médias, 3,2 e 3,4, respectivamente. Sobre a Acessibilidade é possível relacionar tal avaliação ao fato de que a ferramenta Xerte possui limitações para implementação nos quesitos acessibilidade e responsividade. Sobre Conformidade com padrões, a ferramenta Xerte produz OA em conformidade com padrão SCORM, mas essa informação não foi disponibilizada para os avaliadores.

Em relação a questão aberta sobre o OA, os avaliadores deixaram feedbacks bastante relevantes. $\mathrm{O}$ avaliador $\mathrm{A} 1$ diz que na opinião pedagógica: "A plataforma a ser utilizada irá ter que ser refeita todas as vezes que for utilizada para séries e idades diferentes. Seria interessante ter uma aba já direcionada para certos assuntos a fim de que não fosse tão trabalhoso editar a plataforma todas as vezes. A intenção e o designer ficaram ótimos, parabéns!". Sobre esse comentário, o OA não foi desenvolvido para atender diversas séries e idades. Porém, vislumbramos essa possibilidade como continuação futura do trabalho. 
Já o avaliador A2 diz que: "O sistema apresenta uma interface simples, que é de fácil manuseio para qualquer usuário, por ter um personagem relacionado, facilita crianças/adolescentes a se conectarem mais ao projeto". Enquanto o avaliador A5 diz que: "De modo geral acha que crianças e adolescentes conseguem entender os dois conceitos apresentados. O OA desperta um senso crítico, fazendo com que o usuário questione as informações que recebe, além de instruí-lo sobre formas de verificar tais informações". Essas avaliações positivas indicam que o objetivo do OA foi alcançado, sendo um instrumento simples e de fácil utilização.

$\mathrm{O}$ avaliador A1 destaca que a dimensão Acessibilidade possui deficiências, visto que: "Muitas crianças na faixa etária que você preparou o material não possuem total acesso a ferramenta na Internet". Já o avaliador A3 diz que: "No smartphone que tenho, tive problemas com a rolagem nas telas, nada que impossibilite o uso, mas como aconteceu com frequência, acredito que possa ser um fator desmotivante ao usuário."Sobre o acesso a Internet, é condição necessária que o laboratório de informática da escola disponha de Internet para que o OA possa ser utilizado. Como já mencionado, o OA possui algumas questões em relação a responsividade, em especial para visualização em smartphones, porém, pode ser utilizado perfeitamente nos computadores das escolas.

A aplicação do método EGameFlow, para os estudantes, se deu de forma presencial. Como as escolas estavam sem aulas presenciais, devido ao período pandêmico causado pelo vírus Sars-CoV-2 (Covid-19), o número de entrevistados foi reduzido, tendo participado quatro crianças, sendo que $50 \%$ dessas crianças estão regularmente matriculadas no $6^{\circ}$ ano do ensino fundamental II e os outros $50 \%$ estão regularmente matriculadas no $7^{\circ}$ ano do ensino fundamental II. As avaliações com os estudantes foram realizadas um por um, apenas um estudante e o condutor da avaliação. Foram tomadas as medidas de ventilação da área, distanciamento, uso de máscara e álcool em gel.

Na Figura 5 as médias das notas atribuídas por cada avaliador nas dimensões do EGameFlow são apresentadas. O desvio padrão das médias do método EGameFlow obteve uma variação de 0,96 até 2,12 pontos.

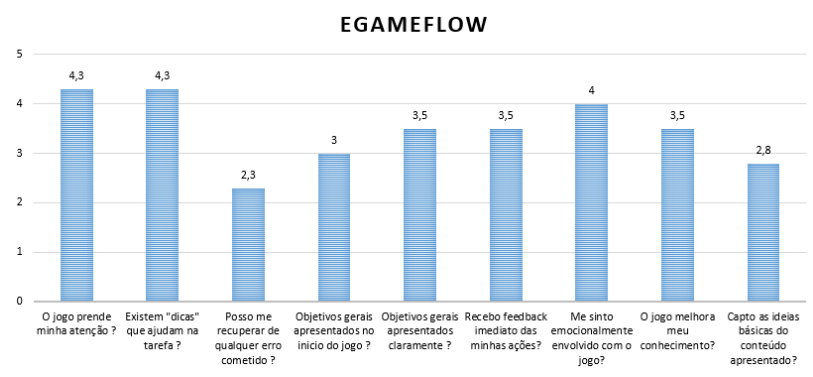

Figura 5: Média das dimensões avaliadas.

As melhores médias, de 4,3 pontos, foram alcançadas pelas dimensões Concentração, que é abrangida pelo item "O jogo prende minha atenção?"e Desafios, com o item "Existem "dicas"que ajudam na tarefa?". Já a dimensão Imersão que é incluída no item "Me sinto emocionalmente envolvido com o jogo?"conquistou 4 pontos. Essas avaliações em quesitos importantes, encorajam a utilização com estudantes.
A dimensão Melhoria de Conhecimento é compreendida pelos itens "O jogo melhora meu conhecimento?"e "Capto as ideias básicas do conteúdo apresentado?"obtiveram 3,5 e 2,8 pontos respectivamente. Era esperada uma avaliação melhor nestes itens, sendo necessário investigar mais nas avaliações futuras.

Na dimensão Clareza dos Objetivos que engloba os itens "Objetivos gerais apresentados no inicio do jogo?"e "Objetivos gerais apresentados claramente?"obtiveram 3 e 3,5 pontos de média, respectivamente. Apesar de os especialistas terem avaliado muito bem os objetivos, 4,3, o mesmo não ocorreu com os estudantes. Esse ponto vai ser melhor investigado nas próximas avaliações.

A dimensão Feedback que compreende o item "Recebo feedback imediato das minhas ações?"obteve 3,5 pontos de média. Já a dimensão Autonomia obteve a menor média dentre as demais com o item "Posso me recuperar de qualquer erro cometido?"tendo apenas 2,3 pontos. Essas avaliações indicam que algumas melhorias podem ser necessárias.

A dimensão Interação Social não foi incluída no processo de avaliação, pois o OA não possui tal componente, portanto sua nota é $N A$. Consideramos que as avaliações realizadas durante o período de pandemia foram introdutórias. Não conseguimos o perfil adequado de avaliadores, com mais estudantes e professores. Entendemos que as avaliações deverão ser repetidas, tão logo possamos ir até a escola. Acreditamos que ao realizar uma oficina presencial com os estudantes no laboratório de informática da escola, conseguiremos captar melhor a avaliação do OA pelo seu público-alvo.

De todo modo, o tema do OA é muito relevante para o período atual e pode suscitar debates e troca de ideias entre estudantes e professores.

\section{CONCLUSÕES}

Neste trabalho abordou-se a temática da cidadania digital com o objetivo de conceber um objeto de aprendizagem que fosse capaz de tratar de forma lúdica conceitos relacionados a fake news e filtros bolha. O OA foi idealizado tendo a rede social Facebook e o jogo digital Tito e os Pássaros como inspiração, sendo desenvolvido um design simples e objetivo.

Realizou-se a aplicação dos métodos LORI e EGameFlow com a finalidade de avaliar conceitos técnicos e pedagógicos do material desenvolvido. Observou-se que a avaliação do método LORI obteve notas satisfatórias nas dimensões de Qualidade do Conteúdo $(4,8)$ e Objetivo de Aprendizagem (4,7), apesar de possuir algumas insuficiências relatadas pelos avaliadores. Já o método EGameFlow obteve notas um pouco abaixo do esperado, principalmente na dimensão Melhoria do Conhecimento que é compreendida pelos itens "O jogo melhora meu conhecimento?"e "Capto as ideias básicas do conteúdo apresentado?"obtiveram 3,5 e 2,8 pontos respectivamente, onde se esperava uma assimilação do conteúdo abordado ao decorrer do OA.

Como trabalho futuro, pós-pandemia, o OA será reavaliado com diversos estudantes do ensino fundamental II e com professores e pedagogos, com o propósito de realizar modificações que visam deixar o conteúdo de forma atraente e dinâmica. Acredita-se que um dos fatores que levou o OA não ser melhor qualificado nas dimensões avaliadas foi o impedimento da aplicação do material no ambiente escolar devido a pandemia. 


\section{REFERÊNCIAS}

[1] Juliano Maurício de Carvalho et al. CIDADANIA DIGITAL: Um estudo do programa brasileiro para a sociedade da informação. $\mathrm{PhD}$ thesis, Universidade Metodista de São Paulo, 2005.

[2] Hunt Allcott and Matthew Gentzkow. Social media and fake news in the 2016 election. Journal of economic perspectives, 31(2):211-36, 2017.

[3] Eduardo Magrani. Democracia conectada: a internet como ferramenta de engajamento político-democrático. Curitiba: ed. Juruá, 2014.

[4] David Arnim Wiley. Learning object design and sequencing theory. $\mathrm{PhD}$ thesis, Brigham Young University, 2000.

[5] Eli Pariser. O filtro invisível: o que a internet está escondendo de você. Editora Schwarcz-Companhia das Letras, 2012.

[6] Sérgio Branco. Fake news e os caminhos para fora da bolha. Associação Interesse Nacional, São Paulo, 10(38):51-61, 2017.

[7] Juliana Braga and Lilian Menezes. Introdução aos objetos de aprendizagem, volume 1. Editora da UFABC, 2014

[8] Poliana Marta Ribeiro de Abreu, Perla Maria Berwanger, and Ramon Bezerra Costa. Gameficação e as fakenews: uma análise do jogo cheque isso! PROfEÇÃO E DOCÊNCIA, 9(2):167-177, 2018.
[9] Paulo Eduardo Battistella, Abner C Rodrigues Neto, Ronaldo LR Campos, Andrei Souza Inácio, Divino I Ribeiro Junior, Ricardo A Silveira, and Aldo von Wangenheim. Classificação de objetos de aprendizagem e análise de ferramentas de autoria. XX Simpósio Brasileiro de Informática na Educação, 2009.

[10] Wilk Oliveira, Sebastião Neto, Clovis Gomes da Silva Junoir, and Ig Ibert Bittencourt. Avaliação de jogos educativos: Uma abordagem no ensino de matemática. In Brazilian Symposium on Computers in Education (Simpósio Brasileiro de Informática na Educação-SBIE), volume 26, page 657, 2015.

[11] Marcos Tsuda, Vinícius Moro Sanches, Thalles Gonçalves Ferreira, Joice Lee Otsuka, and Delano Medeiros Beder. Análise de métodos de avaliação de jogos educacionais. Proceedings of XIII SBGames, pages 12-14, 2014.

[12] John Nesbit, Karen Belfer, and Tracey Leacock. Learning object review instrument (lori), version 1.5. E-Learning Research and Assessment (eLera) and the Portal for Online Objects in Learning (POOL), 2007.

[13] Fong-Ling Fu, Rong-Chang Su, and Sheng-Chin Yu. Egameflow: A scale to measure learners' enjoyment of e-learning games. Computers \& Education, 52(1): 101-112, 2009.

[14] Penelope Sweetser and Peta Wyeth. Gameflow: a model for evaluating player enjoyment in games. Computers in Entertainment (CIE), 3(3):3-3, 2005. 